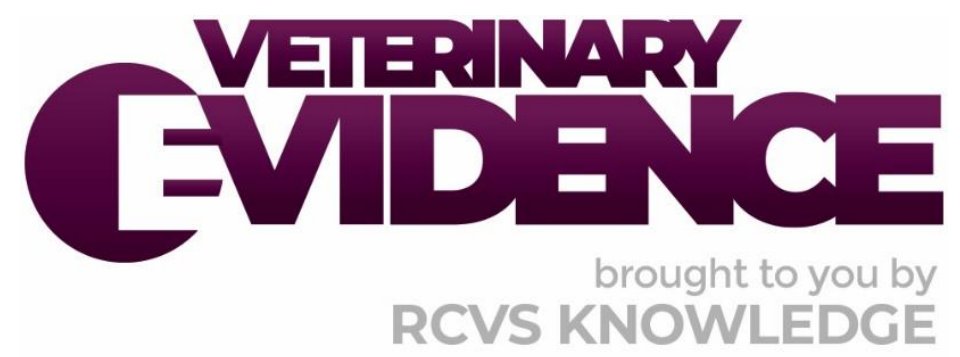

\title{
Trilostane monitoring in canine hyperadrenocorticism: can basal cortisol measurement replace the ACTH stimulation test?
}

\section{A Knowledge Summary by}

Theodora K. Tsouloufi DVM PhD AFHEA MRCVS ${ }^{1 *}$ loannis L. Oikonomidis DVM PhD AFHEA MRCVS ${ }^{1}$

\footnotetext{
${ }^{1}$ The Royal (Dick) School of Veterinary Studies, Easter Bush Campus, Midlothian, EH25 9RG * Corresponding Author (theodora.tsouloufi@gmail.com)
}

ISSN: 2396-9776

Published: 01 Sep 2021

in: The Veterinary Evidence journal Vol 6, Issue 3

DOI: https://doi.org/10.18849/ve.v6i3.412

Reviewed by: Sarah Keir (BVMS PGCertSAM MRCVS) and Constance Neville White (DVM PhD) 


\section{KNOWLEDGE SUMMARY}

\section{PICO question}

In dogs with hyperadrenocorticism that are being treated with trilostane, does the measurement of basal cortisol levels have comparable diagnostic performance to the adrenocorticotropic hormone (ACTH) stimulation test?

\section{Clinical bottom line}

\section{Category of research question}

Diagnosis (effectiveness of treatment monitoring)

\section{The number and type of study designs reviewed}

Four cross-sectional diagnostic accuracy studies were critically reviewed

\section{Strength of evidence}

Weak to moderate (level 2)

\section{Outcomes reported}

There is evidence of moderate strength suggesting that basal cortisol measured at 4-6 hours (and possibly 2-3 hours) post-trilostane can be a good test to exclude adrenal oversuppression, while its use is not suggested for diagnostic confirmation of oversuppression. There is evidence of weak strength that basal cortisol might be helpful for identifying dogs with inadequate adrenal suppression, but cannot be used to rule it out

\section{Conclusion}

Although the evaluation of the available evidence is difficult due to its heterogeneity, there is evidence of moderate strength suggesting that a basal cortisol measured at 4-6 hours (and possibly 2-3 hours) posttrilostane dose can be a good test to rule out adrenal oversuppression, but it cannot be used to definitively diagnose oversuppression. The current evidence suggests that basal cortisol is less useful for the identification of inadequate control. Based on one included study, neither ACTH-stimulated nor basal cortisol levels correlate optimally with the actual clinical response of the patient. In this context, it might be suggested that none of the currently used laboratory tests should be used as a sole monitoring tool in dogs with hyperadrenocorticism receiving trilostane and thus, the assessment of the clinical response is of utmost importance

\section{How to apply this evidence in practice}

The application of evidence into practice should take into account multiple factors, not limited to: individual clinical expertise, patient's circumstances and owners' values, country, location or clinic where you work, the individual case in front of you, the availability of therapies and resources.

Knowledge Summaries are a resource to help reinforce or inform decision making. They do not override the responsibility or judgement of the practitioner to do what is best for the animal in their care. 


\section{The evidence}

Four cross-sectional diagnostic accuracy studies were considered for appraisal based on the predefined inclusion and exclusion criteria. The available studies are characterised by marked heterogeneity, as they report variable cut-offs, trilostane dose intervals and ACTH stimulation test timing, and are therefore, difficult to summarise. Overall, there is evidence of moderate strength suggesting that basal cortisol measured at 4-6 hours (or possibly 2-3 hours) post-trilostane can be a good test to exclude oversuppression, while it cannot be used to confirm oversuppression. There is weak evidence that basal cortisol might be helpful for identifying inadequate adrenal suppression, but not for excluding it.

\section{Abbreviations}

\begin{tabular}{|l|l|}
\hline ACTH & adrenocorticotropic hormone \\
\hline ADH & adrenal-dependent hyperadrenocorticism \\
\hline PDH & pituitary-dependent hyperadrenocorticism \\
\hline PPV & positive predictive value \\
\hline NPV & negative predictive value \\
\hline
\end{tabular}

\section{Summary of the evidence}

\begin{tabular}{|c|c|}
\hline 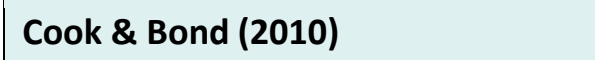 & \\
\hline Population: & $\begin{array}{l}\text { Adult dogs with naturally occurring, PDH or ADH under trilostane } \\
\text { treatment (once and twice daily) }\end{array}$ \\
\hline Sample size: & 103 dogs studied and 342 tests performed \\
\hline Intervention details: & $\begin{array}{l}\text { - ACTH stimulation tests were performed on days } 14,28,42 \\
\text { and } 84 \text { after trilostane treatment initiation (4-6 hours } \\
\text { following trilostane administration). } \\
\text { - For the ACTH stimulation test, } 0.125 \mathrm{mg} \text { for dogs }<5 \mathrm{~kg} \text { and } \\
0.25 \mathrm{mg} \text { for dogs } \geq 5 \mathrm{~kg} \text { of cosyntropin (Cortrosyn }{ }^{\circledR}, \\
\text { Amphastar) was injected intravenously. } \\
\text { - Cortisol concentrations were determined using a } \\
\text { commercially available radioimmunoassay (IDEXX Reference } \\
\text { Laboratories Inc.). }\end{array}$ \\
\hline Study design: & Cross-sectional diagnostic accuracy study \\
\hline Outcome studied: & $\begin{array}{l}\text { Control of adrenal gland function in hyperadrenocorticism, using } \\
\text { post-ACTH serum cortisol concentration as the reference test: } \\
\text { - Excessive control of cortisol release: post-ACTH serum } \\
\text { cortisol concentration }<1.5 \mu \mathrm{g} / \mathrm{dL} \text { (41.4 } \mathrm{nmol} / \mathrm{L}) \\
\text { - Adequate control of cortisol release: post-ACTH serum } \\
\text { cortisol concentration } 1.5-9.1 \mu \mathrm{g} / \mathrm{dL} \text { (41.4-251.1 nmol/L) } \\
\text { - Inadequate control of cortisol release: post-ACTH serum } \\
\text { cortisol concentration }>9.1 \mu \mathrm{g} / \mathrm{dL}(251.1 \mathrm{nmol} / \mathrm{L})\end{array}$ \\
\hline $\begin{array}{l}\text { Main findings: } \\
\text { (relevant to PICO question): }\end{array}$ & $\begin{array}{l}\text { - A statistically significant, positive correlation }(r=0.68 ; \mathrm{P}< \\
0.001) \text { was found between the basal cortisol concentrations } \\
\text { and the cortisol concentrations after ACTH stimulation. } \\
\text { - The optimal cut-off basal cortisol value for oversuppression } \\
[<1.3 \mu \mathrm{g} / \mathrm{dL} \text { ( } 35.9 \mathrm{nmol} / \mathrm{L})] \text { yielded a sensitivity of } 17 / 22 \\
\text { (77\%) and a specificity of } 254 / 320 \text { ( } 79 \%) \text { as compared to the } \\
\text { post-ACTH cortisol concentration. The PPV and NPV values } \\
\text { were } 20 \% \text { and } 98 \% \text {, respectively. }\end{array}$ \\
\hline
\end{tabular}




\begin{tabular}{|c|c|}
\hline & $\begin{array}{l}\text { - The optimal cut-off basal cortisol value for inadequate } \\
\text { suppression [ }>2.9 \mu \mathrm{g} / \mathrm{dL}(80.0 \mathrm{nmol} / \mathrm{L})] \text { yielded a sensitivity } \\
\text { of } 54 / 65(83 \%) \text { and a specificity of } 200 / 277(72 \%) \text { as } \\
\text { compared to the post-ACTH cortisol concentration. The PPV } \\
\text { and NPV values were } 42 \% \text { and } 95 \% \text {, respectively. }\end{array}$ \\
\hline Limitations: & $\begin{array}{l}\text { - Clinical variables were not included in the analysis. } \\
\text { - No stratification of results for PDH and ADH. } \\
\text { - Sample size not calculated. }\end{array}$ \\
\hline
\end{tabular}

\begin{tabular}{|c|c|}
\hline Population: & Adult dogs with PDH under trilostane treatment (once daily) \\
\hline Sample size: & 40 dogs studied and 148 tests performed \\
\hline Intervention details: & $\begin{array}{l}\text { - ACTH stimulation tests were performed } 2-3 \text { hours after } \\
\text { trilostane administration in the morning. } \\
\text { - For the ACTH stimulation test, } 0.25 \text { mg of synthetic ACTH } \\
\text { (Synacthen }{ }^{\circledR} \text {, Novartis Pharma Schweiz Ag) was injected } \\
\text { intravenously. } \\
\text { - Serum cortisol concentration was measured with a solid- } \\
\text { phase chemiluminescent immunoassay (Immulite }{ }^{\circledR} 1000 \text {, } \\
\text { Siemens Healthcare Diagnostics). }\end{array}$ \\
\hline Study design: & Cross-sectional diagnostic accuracy study \\
\hline Outcome studied: & $\begin{array}{l}\text { Control of adrenal gland function in hyperadrenocorticism, using } \\
\text { post-ACTH serum cortisol concentration as the reference test: } \\
\text { - Excessive control of cortisol release: post-ACTH serum } \\
\text { cortisol concentration }<1.5 \mu \mathrm{g} / \mathrm{dL}(41.4 \mathrm{nmol} / \mathrm{L} \text { ) } \\
\text { - Adequate control of cortisol release: post-ACTH serum } \\
\text { cortisol concentration } 1.5-5.4 \mu \mathrm{g} / \mathrm{dL} \text { ( } 41.4-140.7 \mathrm{nmol} / \mathrm{L} \text { ) } \\
\text { - Inadequate control of cortisol release: post-ACTH serum } \\
\text { cortisol concentration }>5.4 \mu \mathrm{g} / \mathrm{dL}(140.7 \mathrm{nmol} / \mathrm{L})\end{array}$ \\
\hline $\begin{array}{l}\text { Main findings: } \\
\text { (relevant to PICO question): }\end{array}$ & $\begin{array}{l}\text { The optimal cut-off basal cortisol value for oversuppression } \\
\text { [ } \leq 1.0 \mu \mathrm{g} / \mathrm{dL} \text { ( } 27.6 \mathrm{nmol} / \mathrm{L})] \text { yielded a reported NPV of } 97 \% \text { as } \\
\text { compared to the post-ACTH cortisol concentration). } \\
\text { However, a large number of dogs with basal cortisol }<1.0 \\
\text { were not oversuppressed, leading to a large (though } \\
\text { unstated/incalculable) number of false positives using this } \\
\text { cut-off (low PPV). } \\
\text { - A basal serum cortisol }>4.4 \mu \mathrm{g} / \mathrm{dL}(121.4 \mathrm{nmol} / \mathrm{L}) \text { correctly } \\
\text { identified inadequate suppression in all cases }(12 \% \text { of total } \\
\text { cases). }\end{array}$ \\
\hline Limitations: & $\begin{array}{l}\text { - Results reported without clear cut-off values, while } \\
\text { - } \text { Rensitivity and specificity values were not explicitly reported. } \\
\text { standard. } \\
\text { - Small sample size. } \\
\text { - Confidence intervals not presented. }\end{array}$ \\
\hline
\end{tabular}




\begin{tabular}{|c|c|}
\hline \multicolumn{2}{|l|}{ Macfarlane et al. (2016) } \\
\hline Population: & $\begin{array}{l}\text { Adult dogs with naturally occurring, PDH or ADH under trilostane } \\
\text { treatment (once and twice daily) }\end{array}$ \\
\hline Sample size: & 67 dogs studied and 110 tests performed \\
\hline Intervention details: & $\begin{array}{l}\text { A questionnaire with nine questions using a Likert scale } \\
\text { response was used by the owners to assess thirst, urine } \\
\text { volume, appetite, panting, exercise tolerance, coat quality, } \\
\text { demeanour, gastrointestinal signs and their overall impression } \\
\text { of the hyperadrenocorticism control and other signs of } \\
\text { progression of the disease. Weighted scores with a minimum } \\
\text { total of } 4 \text { and a maximum total of } 28 \text { points were } \\
\text { retrospectively assigned to the answers. The results of the } \\
\text { questionnaires were retrospectively assessed and categorised } \\
\text { according to a consensus of clinicians who were blinded to the } \\
\text { cases. } \\
\text { The dogs were initially categorised by the clinicians as being } \\
\text { well or unwell based on the owners' answers. Then the dogs } \\
\text { that had been classified as being well were further categorised } \\
\text { as having excellent clinical control (defined as no dose increase } \\
\text { likely required), reasonable clinical control (defined as small } \\
\text { dose increase likely required), and poor clinical control (defined } \\
\text { as large dose increase likely required). } \\
\text { ACTH stimulation tests (n=110) were performed } 3 \text { hours after } \\
\text { trilostane administration. Basal serum cortisol and } 1 \text { hour post- } \\
\text { ACTH serum cortisol concentrations were measured. Pre- } \\
\text { trilostane serum cortisol concentration was measured as well. } \\
\text { For the ACTH stimulation test, } 5 \text { } \mu \text { g/kg of tetracosactide } \\
\text { (Synacthen, Alliance Pharmaceuticals) was injected } \\
\text { intravenously. } \\
\text { Serum cortisol concentration was measured with a solid-phase } \\
\text { chemiluminescent immunoassay (Immulite }{ }^{\circledR} 2000 \text {, Siemens } \\
\text { Healthcare Diagnostics). }\end{array}$ \\
\hline Study design: & Cross-sectional diagnostic accuracy study \\
\hline Outcome studied: & $\begin{array}{l}\text { Clinical control of hyperadrenocorticism, using an owner questionnaire } \\
\text { of standardised clinical history as the reference test. }\end{array}$ \\
\hline $\begin{array}{l}\text { Main findings: } \\
\text { (relevant to PICO question): }\end{array}$ & 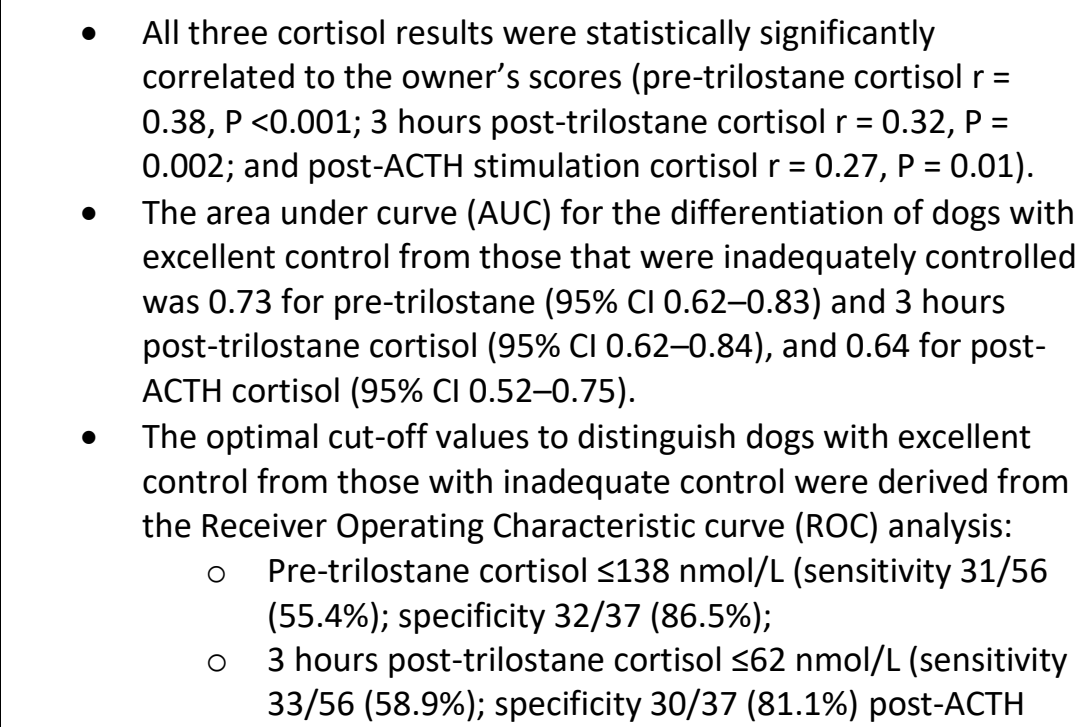 \\
\hline
\end{tabular}




\begin{tabular}{|l|l|l|}
\hline & \multicolumn{1}{c|}{$\begin{array}{c}\text { cortisol } \leq 130 \mathrm{nmol} / \mathrm{L}(\text { sensitivity } 23 / 56(41.1 \%) ; \\
\text { specificity } 26 / 37(70.3 \%)) .\end{array}$} \\
& $\begin{array}{l}\text { The diagnostic accuracy of the above tests for the adrenal } \\
\text { oversuppression was not assessed due to the small number } \\
\text { of included dogs which were oversuppressed. }\end{array}$ \\
\hline Limitations: & $\begin{array}{l}\text { Hyperadrenocorticism was not differentiated into PDH or } \\
\text { ADH. }\end{array}$ \\
& $\begin{array}{l}\text { No dogs included with oversuppression. } \\
\text { - Small sample size. }\end{array}$ \\
& $\begin{array}{l}\text { Difficult to generalise pre-trilostane cut-offs generated from } \\
\text { dogs dosed once daily to those dosed twice daily. }\end{array}$ \\
\hline
\end{tabular}

\begin{tabular}{|c|c|}
\hline \multicolumn{2}{|l|}{ Woolcock et al. (2016) } \\
\hline Population: & $\begin{array}{l}\text { Medical records of adult dogs with PDH under trilostane treatment } \\
\text { (twice daily) }\end{array}$ \\
\hline Sample size: & 22 dogs studied and 109 tests performed \\
\hline Intervention details: & $\begin{array}{l}\text { - Searches were performed between } 1 \text { January } 2008 \text {, and } 31 \\
\text { December 2012. Signalment, comorbidities, electrolyte } \\
\text { concentrations, clinical signs, basal and ACTH-stimulated } \\
\text { cortisol concentrations and potential trilostane dose } \\
\text { adjustments were extracted from the record. } \\
\text { - All ACTH stimulation tests were performed } 4-6 \text { hours after } \\
\text { trilostane administration. } \\
\text { - For the ACTH stimulation test, } 0.125 \mathrm{mg} \text { for dogs }<25 \mathrm{~kg} \text { and } \\
0.25 \mathrm{mg} \text { for dogs } \geq 25 \mathrm{~kg} \text { of cosyntropin (Cortrosyn }{ }^{\circledast} \text {, } \\
\text { Amphastar) was injected intravenously. } \\
\text { Cortisol concentrations were determined using a solid-phase } \\
\text { chemiluminescent immunoassay (Immulite }{ }^{\circledR} 1000 \text {, Siemens } \\
\text { Healthcare Diagnostics). }\end{array}$ \\
\hline Study design: & Retrospective cross-sectional diagnostic accuracy study \\
\hline Outcome studied: & $\begin{array}{l}\text { Control of adrenal gland function in hyperadrenocorticism, using } \\
\text { post-ACTH serum cortisol concentration as the reference test: } \\
\text { - Excessive control of cortisol release: post-ACTH serum } \\
\text { cortisol concentration } \leq 2.0 \mu \mathrm{g} / \mathrm{dL} \text { ( } 55.2 \mathrm{nmol} / \mathrm{L}) \text {. }\end{array}$ \\
\hline $\begin{array}{l}\text { Main findings: } \\
\text { (relevant to PICO question): }\end{array}$ & $\begin{array}{l}\text { - A statistically significant moderate positive correlation ( } r= \\
0.64 ; \mathrm{P}<0.001) \text { was found between the basal cortisol } \\
\text { concentrations and the cortisol concentrations after ACTH } \\
\text { stimulation. } \\
\text { - The optimal cut-off basal cortisol value for oversuppression } \\
{[\leq 1.3 \mu \mathrm{g} / \mathrm{dL}(35.9 \mathrm{nmol} / \mathrm{L})] \text { yielded a NPV of } 93 \% \text {. }} \\
\text { - The diagnostic accuracy of basal cortisol for inadequate } \\
\text { adrenal suppression was not reported. }\end{array}$ \\
\hline Limitations: & Small sample size. \\
\hline
\end{tabular}


Canine hyperadrenocorticism or Cushing's syndrome is an endocrine disorder in middle-aged and older dogs, which is caused by the excessive secretion of ACTH by the pituitary gland (PDH) or the presence of a functional adrenocortical tumour (ADH). In the last 20 years, trilostane, a competitive inhibitor of $3 \beta$-hydroxysteroid dehydrogenase, has become the treatment of choice for PDH. However, the ideal method for monitoring trilostane therapy in dogs with hyperadrenocorticism is still debated; specifically, where there is uncertainty in the current evidence regarding the best available test (objective, specific, or sensitive) (Burkhardt et al., 2013). The results from such a test should complement the clinical history and physical examination findings (Bonadio et al., 2014). The ACTH stimulation test, which is conventionally used for monitoring purposes in clinical practice, presents specific limitations, such as questionable monitoring reliability that has not been fully validated and a current lack of consensus regarding timing after trilostane administration (Behrend, 2015). Moreover, it entails the use of synthetic ACTH, which can be expensive and sometimes of limited availability, and its results may not correlate well with the clinical response of the patient, potentially leading to contradictory results (Wehner et al., 2014; Boretti et al., 2016; and Lemetayer \& Blois, 2018). Various alternative monitoring endpoints, such as endogenous plasma ACTH concentration, urine cortisol to creatinine ratio and serum basal cortisol concentration before and/or after the administration of trilostane, have been investigated and have exhibited variable performance (Arenas Bermejo et al., 2020). Basal cortisol concentration measurement, in particular, has been studied the most and some feel it is a promising alternative to the conventionally used ACTH stimulation test (Cook \& Bond, 2010; and Macfarlane et al., 2016).

The currently available literature does not suggest a clear choice between basal cortisol (pre- or posttrilostane) and the ACTH stimulation test. Although the included studies indicate that basal cortisol alone cannot be used as a sole monitoring endpoint, they provide evidence that basal cortisol may be helpful for monitoring the specific outcomes of adrenal oversuppression or inadequate suppression. With regard to the identification of oversuppression, Cook \& Bond (2010) and Woolcock et al. (2016) reported that an optimal basal cortisol cut-off value of $>1.3 \mu \mathrm{g} / \mathrm{dL}(35.9 \mathrm{nmol} / \mathrm{L})$ when measured $4-6$ hours post-trilostane had high specificity for ruling out oversuppression (using the ACTH stimulation test as the reference test). Importantly the NPV of this cut-off was similarly high in both studies ( $95 \%$ and $93 \%$, respectively), indicating that a basal cortisol $\geq 1.3 \mu \mathrm{g} / \mathrm{dL}$ ( $35.9 \mathrm{nmol} / \mathrm{L})$ is highly accurate for excluding oversuppression. However, the PPV in both studies were very low suggesting that a basal cortisol concentration $<1.3 \mu \mathrm{g} / \mathrm{dL}(35.9 \mathrm{nmol} / \mathrm{L})$ cannot be used to confirm oversuppression. Similar results were reported by Burkhardt et al. (2013) with a slightly different basal cortisol cut-off (>1 $\mathrm{\mu g} / \mathrm{dL}(27.6 \mathrm{nmol} / \mathrm{L})$, measured $2-3$ hours post-trilostane) in excluding oversuppression, which yielded an NPV of $97 \%$ (using the ACTH stimulation test as the reference test). A basal cortisol $<1 \mu \mathrm{g} / \mathrm{dL}$ was reported to lack specificity for confirmation of oversuppression in this study although specificity and PPV indices were not reported (nor could be calculated from the presented data).

With regard to the identification of inadequate suppression, Cook \& Bond (2010), reported that their optimal basal cortisol cut-off value for inadequate suppression $(>2.9 \mu \mathrm{g} / \mathrm{dL}(80.0 \mathrm{nmol} / \mathrm{L}))$, measured $4-6$ posttrilostane, had moderate sensitivity and specificity (using the ACTH stimulation test as the reference standard). Although the PPV was very low, the NPV was $95 \%$ indicating that a cortisol value below this cut-off could be used to exclude inadequate suppression. Burkhardt et al. (2013) reported that a basal cortisol cut-off value of $>4.4 \mu \mathrm{g} / \mathrm{dL}(121.4 \mathrm{nmol} / \mathrm{L})$ measured 2-3 hours post-trilostane yielded a low sensitivity and NPV but a specificity and PPV of $100 \%$ (using the ACTH stimulation test as the reference standard). In this study, a basal cortisol value of $>4.4 \mu \mathrm{g} / \mathrm{dL}(121.4 \mathrm{nmol} / \mathrm{L})$ could be used to accurately identify inadequate suppression but many patients with inadequate suppression had basal cortisol measures below $4.4 \mu \mathrm{g} / \mathrm{dL}$. Using a different standard of disease control (clinical score determined by owner questionnaire), Macfarlane et al. (2016), found that pre-trilostane or 3 hours post-trilostane basal cortisol $(>5 \mu \mathrm{g} / \mathrm{dL}(138 \mathrm{nmol} / \mathrm{L})$ and $>2.2 \mu \mathrm{g} / \mathrm{dL}(62 \mathrm{nmol} / \mathrm{L})$, respectively) exhibited a low sensitivity and a moderate to high specificity in identifying inadequately suppressed patients. PPV was $86 \%$ and $83 \%$ for these cut-offs, respectively, indicating that a cortisol value above these cut-offs was moderately accurate in identifying dogs with inadequate suppression. However, the NPV was low suggesting that a cortisol value below these cut-offs could not be used to rule out inadequate suppression. 
Overall, the appraisal of the strength of the existing evidence is rather elusive, as the comparability of the so far published studies is limited. Specifically, there is considerable heterogeneity in the respective study designs employed, especially with regard to the condition (i.e. PDH, ADH or both), trilostane dosing schemes (once or twice daily), the post-ACTH cortisol target ranges and the timing of the basal cortisol measurement or the ACTH stimulation test after the trilostane administration, which might account for the certain amount of variability in the results presented. This is indicative of the current lack of clear consensus regarding different aspects of the monitoring protocols, which could potentially affect future research iterations. With regard to the trilostane dosing scheme, for instance, the results reported in the studies in which trilostane is dosed once daily cannot be extrapolated to those with a twice daily dose, as different treatment effectiveness is expected (Alenza et al., 2006). The timing of the ACTH stimulation test, in turn, seems to be one of the most inconsistent aspects in the available studies; the results of the ACTH stimulation test are affected by the time between the most recent trilostane administration and the test and the current label recommendation is to perform it 4-6 hours after trilostane administration (Arenas Bermejo et al., 2020). This recommendation, however, was derived from dogs receiving mitotane treatment and has not been validated in dogs treated with trilostane (Ramsey, 2010). Published studies report that post-ACTH stimulation test cortisol concentrations vary with the different intervals between trilostane dosing and timing of the test (Alenza et al., 2006). It is therefore, unsurprising that most practitioners recommend in the duration of the monitoring protocol that all subsequent ACTH stimulation tests should be performed at the same time after trilostane administration, in order to ensure consistency in the results. Another point that limits the comparability of the available studies is the use of different reference standards for the confirmation of disease control, with three out of four studies using the ACTH stimulation test, and one using the patient's clinical response as perceived by its owner; while the latter was conducted in a structured way, i.e. use of validated questionnaires, the introduction of subjective bias in the clinical evaluation of the dogs cannot be excluded. On the other hand, it should be highlighted that although the ACTH stimulation test is widely used as a reference standard for the monitoring of adrenal control, this seems to exhibit questionable performance and hence, its use should be critically considered. In three recently published studies, for instance, no (Wehner et al., 2014; and Boretti et al., 2016) or moderate (Macfarlane et al., 2016) correlation was noted between clinical response as perceived by the owners and post-trilostane basal or ACTH-stimulated cortisol. Notwithstanding the above, it should be noted that the current evidence base generally comprises studies with an appropriate design to determine diagnostic accuracy, such as description of the study methods to permit replication, the application of the index test and the reference standard in all study individuals (although an independent, blinded comparison between the two tests is mentioned in only one study), as well as the calculation of subjective measures of test performance and predictive values. Furthermore, previously validated methods with known good performance were used in all of the studies for the measurement of cortisol, which has at least minimised the analytical variability of the results reported; however, the interlaboratory variability should also be taken into consideration.

\section{Confidence in the available evidence and limitations}

The currently available evidence base comprises a good number of cross-sectional diagnostic accuracy studies with clear population inclusion criteria and explicitly described test procedures; however, the studies entail unclear risk of bias and applicability concerns as assessed with the QUADAS-2 tool, which are mostly attributed to the unknown performance of the reference tests and the lack of clarity around the population selection process or the blinding to the reference test results (Table 1). Considering the latter along with the significant heterogeneity in study designs identified, we can conclude that the confidence in the currently available evidence is low to moderate (Grading of Recommendations, Assessment, Development and Evaluations (GRADE) framework - Balshem et al., 2011) and this should be taken into account before attempting to implement these findings into clinical practice. Specifically, the highest level of confidence should be placed in the use of post-trilostane basal cortisol for the exclusion of adrenal oversuppression; there is also evidence that post-trilostane basal cortisol might also be useful for identifying dogs with inadequate suppression, however, lower confidence should be placed on this, as it needs to be confirmed in future studies. Another point that should be highlighted is that the lack of consensus or standards with regard to the monitoring 
protocols for hyperadrenocorticism, the trilostane dosing schemes and the target post-ACTH cortisol concentration introduces additional limitations to the current evidence base as it does not allow for direct comparisons.

\begin{tabular}{|c|c|c|c|c|c|c|c|}
\hline \multirow[b]{2}{*}{ Study } & \multicolumn{4}{|c|}{ Risk of bias } & \multicolumn{3}{|c|}{ Applicability concerns } \\
\hline & $\begin{array}{l}\text { Patient } \\
\text { selection }\end{array}$ & Index test & $\begin{array}{l}\text { Reference } \\
\text { standard }\end{array}$ & $\begin{array}{l}\text { Flow and } \\
\text { timing }\end{array}$ & $\begin{array}{l}\text { Patient } \\
\text { selection }\end{array}$ & Index test & $\begin{array}{l}\text { Reference } \\
\text { standard }\end{array}$ \\
\hline $\begin{array}{l}\text { Cook and } \\
\text { Bond, } \\
2010\end{array}$ & $?$ & $?$ & ? & $\mathrm{L}$ & $\mathrm{L}$ & $?$ & ? \\
\hline $\begin{array}{l}\text { Burkhardt } \\
\text { et al, } 2013\end{array}$ & $?$ & $?$ & ? & $\mathrm{L}$ & $\mathrm{L}$ & $?$ & $?$ \\
\hline $\begin{array}{l}\text { Macfarlane } \\
\text { et al, } 2016\end{array}$ & ? & $\mathrm{L}$ & $?$ & $L$ & $L$ & $L$ & ? \\
\hline $\begin{array}{l}\text { Woolcock } \\
\text { et al, } 2016\end{array}$ & $?$ & $?$ & $?$ & $\mathrm{~L}$ & $\mathrm{~L}$ & $?$ & $?$ \\
\hline
\end{tabular}

Table 1. Tabular presentation of the QUADAS-2 results for the studies included in this Knowledge Summary $\mathrm{H}$, high risk; L, low risk; ?, unclear risk (Whiting et al., 2011)

\section{Conclusion and implications for practitioners}

In conclusion, although the evaluation of the available evidence is difficult due to its heterogeneity, there is a significant indication that a basal cortisol measured at 4-6 hours post-trilostane or possibly 2-3 hours posttrilostane can be a good test to exclude adrenal oversuppression, and a basal cortisol measured 2-3 hours post-trilostane might be a helpful test for identifying inadequate suppression. Conversely, the current literature suggests that basal cortisol should not be used to confirm oversuppression or to exclude inadequate suppression. With regard to the conventionally used ACTH stimulation test, clinicians should be mindful that this test has, to date, not been fully validated for trilostane monitoring; it is vital that any monitoring test is correlated to clinical signs. Prospective, multicentre studies with standardised design are required to ensure comparability of results and reach clinically useful conclusions. Additional studies that compare both the ACTH stimulation test and the patient's clinical response as reference standards or incorporate subjective information about patient's clinical status may help to further clarify the clinical utility of basal cortisol measurement. Importantly, consensus guidelines with regard to trilostane monitoring in hyperadrenocorticism would be particularly useful in order to inform clinically relevant decisions.

\section{Methodology Section}

\begin{tabular}{|c|c|}
\hline $\begin{array}{l}\text { Databases searched and dates } \\
\text { covered: }\end{array}$ & $\begin{array}{l}\text { CAB Abstracts on OVID Platform [1984 - April 2021] } \\
\text { PubMed on NCBI interface [1920 - April 2021] }\end{array}$ \\
\hline Search terms: & $\begin{array}{l}\text { CAB Abstracts: } \\
\text { 1. (dog or dogs or canine* OR bitch*).mp. OR exp dogs/ OR ex } \\
\text { bitches/ } \\
\text { 2. (cushing* OR hyperadrenocorticism OR hypercortisolism Of } \\
\text { PDH or ADH).mp. OR exp cushing's syndrome/ } \\
\text { 3. (trilostane OR Vetoryl OR Desopan OR Modrastane OR } \\
\text { Modrenal).mp. } \\
\text { 4. ((basal OR baseline OR plasma OR serum OR blood) AND } \\
\text { cortisol).mp. } \\
\text { 5. (Adrenocorticotropic hormone OR ACTH OR Synacthen OR } \\
\text { tetracosact* OR Cosyntropin OR Cortrosyn).mp. } \\
\text { 6. } 1 \text { AND } 2 \text { AND } 3 \text { AND } 4 \text { AND } 5\end{array}$ \\
\hline
\end{tabular}


PubMed:

1. dog OR dogs OR canine OR bitch*

2. "cushing syndrome" OR Cushing's OR hyperadrenocorticism OR hypercortisolism OR PDH OR ADH

3. trilostane OR "trilostane treated" OR Vetoryl

4. cortisol OR "basal cortisol" OR "baseline cortisol" or "plasma cortisol" OR "serum cortisol" OR "blood cortisol" OR "cortisol levels" OR "cortisol concentration"

5. "Adrenocorticotropic Hormone" OR ACTH OR "ACTH stimulation test" OR "ACTH test" OR Synacthen or tetracosact* or Cosyntropin or Cortrosyn

6. 1 AND 2 AND 3 AND 4 AND 5

Dates searches performed: $20 \mathrm{Apr} 2021$

\section{Exclusion / Inclusion Criteria}

For the purposes of this PICO, only original research articles were considered for inclusion, as the aim was to investigate measures of test performance (i.e. quantitative data) and thus, sources of qualitative evidence (i.e. expert opinion articles, narrative reviews) were excluded even if relevant. Conference abstracts were excluded as they were not likely to provide the level of detail needed for the appraisal of the evidence. Both authors performed the study screening by applying the predefined inclusion and exclusion criteria. Potential discrepancies were resolved by discussion. The study screening was performed at a title/abstract level and subsequently, at a full-text level. The references of each article considered for inclusion were screened for additional articles that were not retrieved by the initial search strategy.

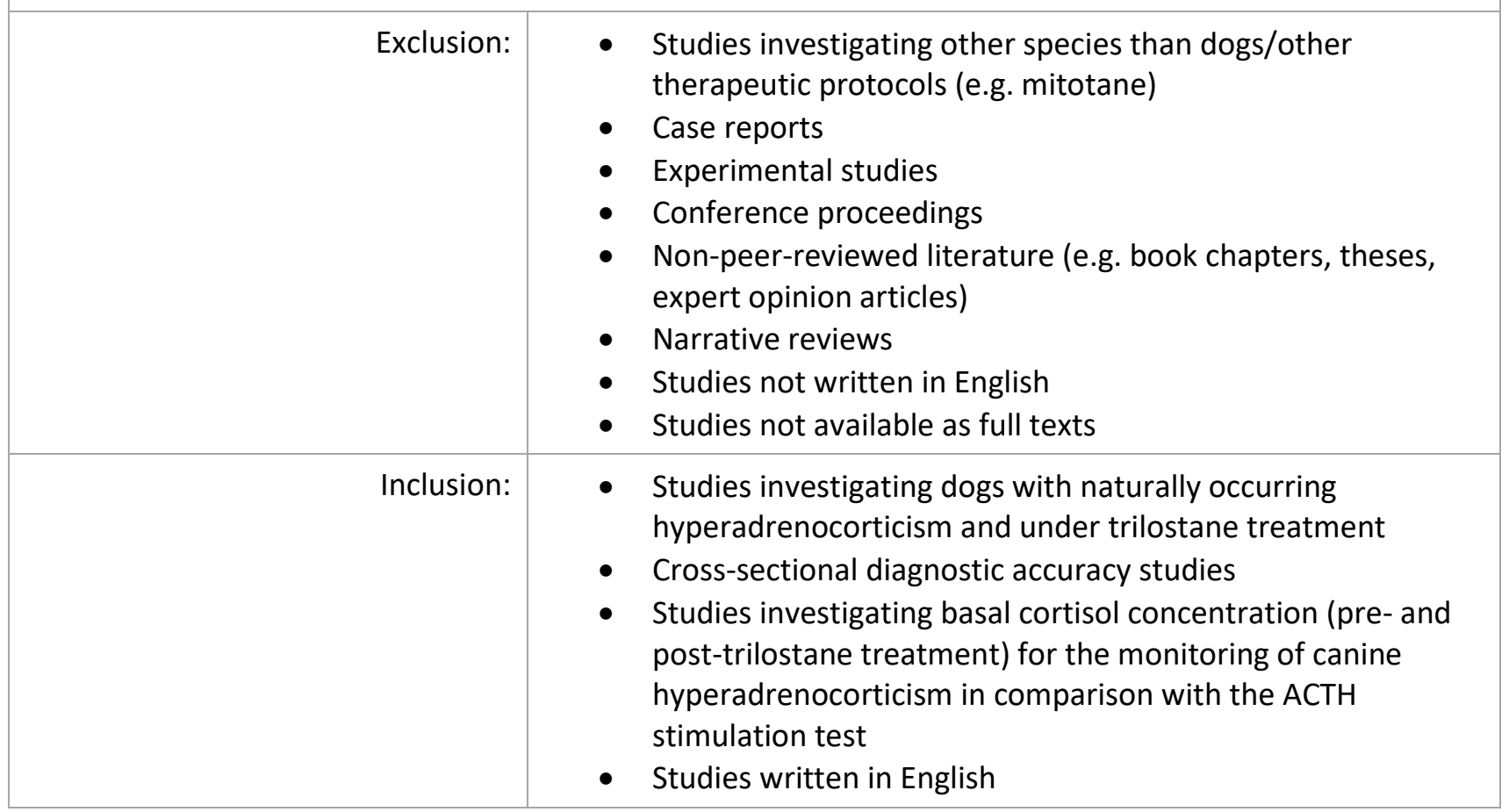




\begin{tabular}{|c|c|c|c|c|c|c|}
\hline \multicolumn{7}{|c|}{ Search Outcome } \\
\hline Database & $\begin{array}{c}\text { Number } \\
\text { of } \\
\text { results }\end{array}$ & $\begin{array}{l}\text { Excluded - } \\
\text { Not } \\
\text { written in } \\
\text { English }\end{array}$ & $\begin{array}{c}\text { Excluded - Not } \\
\text { relevant to } \\
\text { PICO }\end{array}$ & $\begin{array}{c}\text { Excluded - Case } \\
\text { reports, } \\
\text { Experimental } \\
\text { studies, } \\
\text { Narrative } \\
\text { reviews }\end{array}$ & $\begin{array}{l}\text { Excluded - } \\
\text { Conference } \\
\text { proceedings }\end{array}$ & $\begin{array}{c}\text { Total } \\
\text { relevant } \\
\text { papers }\end{array}$ \\
\hline $\begin{array}{l}\text { CAB } \\
\text { Abstracts }\end{array}$ & 46 & 5 & 26 & 10 & 2 & 3 \\
\hline PubMed & 45 & 0 & 33 & 8 & 0 & 4 \\
\hline \multicolumn{6}{|c|}{ Total relevant papers when duplicates removed } & 4 \\
\hline
\end{tabular}

\section{CONFLICT OF INTEREST}

The authors declare no conflict of interest.

\section{REFERENCES}

1. Alenza, D.P., Arenas, C., Lopez, M.L. \& Melian, C. (2006). Long-Term Efficacy of Trilostane Administered Twice Daily in Dogs With Pituitary-Dependent Hyperadrenocorticism. Journal of the American Animal Hospital Association. 42(4), 269-276. DOI: http://dx.doi.org/10.5326/0420269

2. Arenas Bermejo, C.A., Alenza, D.P., San José, P.G., Llauet, L., Pérez-López, L., Melián, C. \& Feldman, E.C. (2020). Laboratory assessment of trilostane treatment in dogs with pituitary-dependent hyperadrenocorticism. Journal of Veterinary Internal Medicine.34(4), 1413-1422.

DOI: https://doi.org/10.1111/jvim.15830

3. Balshem, H., Helfand, M., Schunemann, H.J., Oxman, A.D., Kunz, R., Brozek, J., Vist, G.E., Falck-Ytter, Y., Meerpohl, J., Norris, S. \& Guyatt, G.H. (2011). GRADE guidelines: 3. Rating the quality of evidence. Journal of Clinical Epidemiology. 64(4), 401-406.

DOI: https://doi.org/10.1016/i.jclinepi.2010.07.015

4. Behrend, E. (2015). Canine hyperadrenocorticism. In: E. Feldman, R. Nelson, C. Reusch \& J. ScottMoncrieff, ed., Canine and Feline Endocrinology, $4^{\text {th }}$ St Louis: Elsevier, 377-451.

5. Bonadio, C.M., Feldman, E.C., Cohen, T.A. \& Kass, P.H. (2014). Comparison of Adrenocorticotropic Hormone Stimulation Test Results Started 2 versus 4 Hours after Trilostane Administration in Dogs with Naturally Occurring Hyperadrenocorticism. Journal of Veterinary Internal Medicine. 28(4), 12391243. DOI: http://dx.doi.org/10.1111/ivim.12357

6. Boretti, F.S., Holzthuem, J., Reusch, C.E. \& Sieber-Ruckstuhl, N.S. (2016). Lack of association between clinical signs and laboratory parameters in dogs with hyperadrenocorticism before and during trilostane treatment. Schweizer Archiv für Tierheilkunde. 158(9), 631-638.

DOI: http://dx.doi.org/10.17236/sat00083

7. Burkhardt, W.A., Boretti, F.S., Reusch, C.E. \& Sieber-Ruckstuhl, N.S. (2013). Evaluation of Baseline Cortisol, Endogenous ACTH, and Cortisol/ACTH Ratio to Monitor Trilostane Treatment in Dogs with 
Pituitary-Dependent Hypercortisolism. Journal of Veterinary Internal Medicine. 27(4), 919-923.

DOI: http://dx.doi.org/10.1111/jvim.12111

8. Cook, A.K. \& Bond, K.G. (2010). Evaluation of the use of baseline cortisol concentration as a monitoring tool for dogs receiving trilostane as a treatment for hyperadrenocorticism. Journal of the American Veterinary Medical Association. 237(7), 801-805. DOI: http://dx.doi.org/10.2460/javma.237.7.801

9. Lemetayer, J. \& Blois, S. (2018). Update on the use of trilostane in dogs. The Canadian Veterinary Journal. 59(4), 397-407. Available from: https://www.ncbi.nlm.nih.gov/pmc/articles/PMC5855282/ [Accessed 20/04/2021]

10. Macfarlane, L., Parkin, T. \& Ramsey, I. (2016). Pre-trilostane and three-hour post-trilostane cortisol to monitor trilostane therapy in dogs. Veterinary Record. 179(23), 597.

DOI: http://dx.doi.org/10.1136/vr.103744

11. Ramsey, I.K. (2010). Trilostane in dogs. Veterinary Clinics of North America: Small Animal. 40(2), 26983. DOI: http://dx.doi.org/10.1016/j.cvsm.2009.10.008

12. Wehner, A., Gloeckner, S., Sauter-Louis, C., Kruse, D., Stockhaus, C. \& Hartmann, K. (2013). Association between ACTH stimulation test, clinical signs, and laboratory parameters in dogs with hyperadrenocorticism treated with trilostane. Journal of Veterinary Internal Medicine. 28, DOI: http://dx.doi.org/10.1111/jvim.12278

13. Whiting, P.F., Rutjes, A.W., Westwood, M.E., Mallett, S., Deeks, J.J., Reitsma, J.B., Leeflang, M.M.G., Sterne, J.A.C., Bossuyt, P.M. \& the QUADAS-2 Group. (2011). QUADAS-2: A Revised Tool for the Quality Assessment of Diagnostic Accuracy Studies. Annals of Internal Medicine. 155, 529-536. DOI: http://dx.doi.org/10.7326/0003-4819-155-8-201110180-00009

14. Woolcock, A.D., Bugbee, A.C. \& Creevy, K.E. (2016). Evaluation of baseline cortisol concentration to monitor efficacy of twice-daily administration of trilostane to dogs with pituitary-dependent hyperadrenocorticism: 22 cases (2008-2012). Journal of the American Veterinary Medical Association. 248(7), 814-821. DOI: http://dx.doi.org/10.2460/javma.248.7.814 


\section{EVIIDEFeE

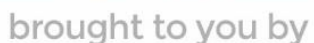 \\ RCVS KNOWLEDGE}

\section{Intellectual Property Rights}

Authors of Knowledge Summaries submitted to RCVS Knowledge for publication will retain copyright in their work, and will be required to grant RCVS Knowledge a non-exclusive license of the rights of copyright in the materials including but not limited to the right to publish, re-

publish, transmit, sell, distribute and otherwise use the materials in all languages and all media throughout the world, and to license or permit others to do so.

\section{Disclaimer}

Knowledge Summaries are a peer-reviewed article type which aims to answer a clinical question based on the best available current evidence. It does not override the responsibility

of the practitioner. Informed decisions should be made by considering such factors as individual clinical expertise and judgement along with patient's circumstances and owners' values. Knowledge Summaries are a resource to help inform and any opinions expressed within the Knowledge Summaries are the author's own and do not necessarily reflect the view of the RCVS Knowledge. Authors are responsible for the accuracy of the content. While the

Editor and Publisher believe that all content herein are in accord with current recommendations and practice at the time of publication, they accept no legal responsibility

for any errors or omissions, and make no warranty, express or implied, with respect to material contained within.

For further information please refer to our Terms of Use.

RCVS Knowledge is the independent charity associated with the Royal College of Veterinary Surgeons (RCVS). Our ambition is to become a global intermediary for evidence based veterinary knowledge by providing access to information

that is of immediate value to practicing veterinary professionals and directly contributes to evidence based clinical decision-making.

https://www.veterinaryevidence.org/

RCVS Knowledge is a registered Charity No. 230886.

Registered as a Company limited by guarantee in England and Wales No. 598443.

Registered Office: Belgravia House, 62-64 Horseferry Road, London SW1P 2AF

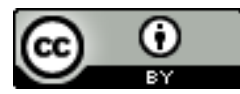

This work is licensed under a Creative Commons Attribution 4.0 International License 